\title{
EL ABAD, SU MANCEBA Y \\ UN ACERTIJO FOLCLÓRICO PANEUROPEO GLOSADO POR SEBASTIÁN DE HOROZCO
}

Sebastián de Horozco, en su Teatro universal de Proverbios (fechado entre 1560-1580), glosaba y explicaba en cuatro quintillas una especie de enigma de cuatro versos que tomó seguramente de la tradición popular:

El abbad y su manceba, y el herrero y su muger de tres güevos comen sendos, esto [i] cómo puede ser[?]

Si quies saber por entero de este caso la berdad la que es muger del herrero es manceba del abbad y ambos tiran a un terrero.

Assí que no es cosa nueva a quien lo quiera entender el abbad y su mançeba el herrero y su muger ser tres personas de prueva.

Mientras el herrero maja el abbad leer la beza después el otro trabaja mientras el clérigo reça en atestarle la paja.

Luego siéntanse a comer los señores reverendos 
con su manceba y muger

de tres güevos comen sendos, de este modo puede ser ${ }^{1}$.

En el Manuscrito 3915 de la Biblioteca Nacional de Madrid, compilado hacia 1620 por el músico Jacinto López, está anotada otra versión del tradicional enigma:
El abad i su manseba, el herrero i su muger, de dos güebos comen sendos esto cómo puede $\operatorname{ser}^{2}$.

$\mathrm{Y}$ en el Vocabulario de refranes y frases proverbiales de Gonzalo Correas, fechado en 1627, aparece, con la anotación de "fázil enima”, una tercera versión de la tradicional cuarteta glosada por Horozco:
El abad i su manzeba, el barvero i su muxer, de tres güevos komen sendos, esto, ¿kómo puede ser??

La solución del "enima" es, desde luego, tan "fázil" como avanzó Correas: la manceba del abad debe de ser la mujer del herrero, lo que explica que el abad, la mujer y el herrero puedan repartirse sin problemas los tres huevos en cuestión. La picardía y tono anticlerical que informa esta adivinanza está también presente en otras estrofillas, relacionadas con ella, anotadas por Correas:

El abad i su vezino, todos muelen en un molino.

${ }^{1}$ Véase la ed. de J. L. Alonso Hernández, Universidad de Groningen-Universidad de Salamanca, Groningen-Salamanca, 1986, núm. 854. Cf. Margit Frenk, Corpus de la antigua lírica popular hispánica. (Siglos xv a xvii), Castalia, Madrid, 1987, núm. 1459; y Suplemento al Corpus de la antigua lírica popular hispánica, Castalia, Madrid, 1992, núm. 1459.

2 [Cancionero] de la mano y pluma de Jacinto López, músico de su Magestad, f. 320; cf. Frenk, Corpus, núm. 1459, que transcribe huebos. Véase además, en el mismo Manuscrito y página, la estrofa "El abad i su manseua / dizen que quieren beuer / dízeles el bachiler / asta que no se puedan ber" (cf. Corpus, núm. 1850).

${ }^{3}$ Véase la ed. de L. Combet, Université, Bordeaux, 1967, p. 85. Cf. Frenk, Corpus, núm. 1459. 
El abad i su vezino, el kura y el sakristán, todos muelen en un molino; ¡ké buena harina harán!

El kura i el sakristán, el barvero i su vezino, todos muelen en un molino; ¡i ké buena harina harán!4

La explicación de Correas a estos dos últimos curiosos poemas vuelve a relacionarlos con el género y la solución de los enigmas que conocimos al principio: "Los onbres pueden ser dos deklarados, «abad i vezino» por «kura i sakristán»”; o, más claramente, "el sakristán es: el barvero; el kura: el vezino; kon ke, pareziendo kuatro no son más de dos". "Lo que no explica Correas es que el cura-abad se acuesta con la mujer del barbero-sacristán su vecino", aclara Margit Frenk ${ }^{5}$ con toda razón, conclusión reforzada además por el hecho de que el "molino" donde muelen todos estos personajes es indudablemente una metáfora erótica del sexo femenino ${ }^{6}$. Explicación muy acorde, por añadidura, con la picante reputación que desde muy antiguo acompaña a las amas de clérigos ${ }^{7}$.

${ }^{4}$ Correas, Vocabulario, pp. 85 y 106. Cf. Frenk, Corpus, núms. 1848 A y 1848 B.

${ }^{5}$ En Frenk, Corpus, núm. 1848B.

${ }^{6}$ Sobre las abundantes referencias literarias al doble sentido erótico de los molinos y de la actividad de moler, cf. la exhaustiva bibliografía que ofrece $\mathrm{SA}_{\mathrm{A}}$ MUel G. Armistead en The Spanish tradition in Louisiana, t. 1: Isleño folkliterature, Juan de la Cuesta, Newark, 1992, pp. 86-88; y yo en mi libro Las dos sirenas y otros estudios de literatura tradicional, Siglo XXI, Madrid, 1995, pp. 280-281. Súmense a las referencias que aparecen en estas páginas las de EQUIPO A. P., O clero na literatura popular galega: cancioneiro e refraneiro, Akal, Madrid, 1975, pp. 37-38; ANTxOn Sorondo, "La molinería en la danza y en la música", Revista de Folklore, 1989, núm. 101, 167-168; GERMÁN DíEz BARRIO, "El molino y el molinero en el refranero", Revista de Folklore, 1989, núm. 101, 178-180; y Augustin Redondo, "De molinos, molineros y molineras: tradiciones folklóricas y literarias del Siglo de Oro", Revista de Folklore, 1989, núm. 102, 183-191.

${ }^{7}$ Sobre la difusión del tópico en la literatura española del Renacimiento, puede verse Francisco Rico, "La manceba del abad", Problemas del "Lazarillo", Cátedra, Madrid, 1987, pp. 173-176. La cuestión recibió un trato a veces polémico e irónico, como demuestra el pliego titulado "Defensa de las maiordomas dels capellans", sobre el que se puede ver ENRIQUe RodRíguez CEPEDA, Romancero impreso en Cataluña (Imprenta de B. Pla y Viuda Pla) 1770-1865, J. Porrúa Turanzas, Madrid, 1984, t. 1, p. 189; y Pedro M. Cátedra, "Sobre literatura popular del Segle xVII (Impresos d'Antoni Lacavalleria)", Estudis de literatura catalana en honor de Josep Romeu i Figueras, eds. L. Badia y J. Massot i Muntaner, Associació Internacional de Llengua i Literatura Catalana-Universitat Autònoma de BarcelonaPublicacions de l'Abadia de Montserrat, Barcelona-Montserrat, 1986, t. 1, pp. 241-257, 256-257. Su arraigo en la literatura popular está atestiguado, por ejemplo, en EQuipo A. P., op. cit., pp. 17-22. En realidad, desde la Edad Media 
Antes de continuar analizando el enigma que tan tradicional y difundido debió ser en la España de los siglos xvi y xvII, daremos un pequeño rodeo para conocer una composición anotada en el Cancionero del Bachiller Jhoan López de fines del siglo Xvi. Aunque su protagonista, Teresa, no sea ama de clérigo, una lectura cuidadosa del poema sugiere que se basa en un tipo de equívoco erótico parecido, y acaso inspirado, por el de los poemas que acabamos de conocer; ya que Teresa tiene todas las trazas de ser, efectivamente, mujer del ingenuo Bras y compañera de juegos sexuales de Antón:

corrían todo tipo de rumores e historias sobre las dudosas costumbres de las amas de curas y su castigo tras la muerte. Véase al respecto de GASTON RAYNAUD, "Des avocas de La jument au deable de Luque la Maudite: trois dits tirés d'un nouveau manuscrit de fableaux", Ro, 12 (1883), p. 219. Muchas canciones modernas inciden en el tópico del trato sexual de los curas con sus amas. Dos que grabé al rabelista Donato Muñoz, nacido en Valdeprado del Río (Cantabria) en 1919 y entrevistado en Nestar (Palencia) el 12 de julio de 1989, dicen: "El cura le dijo al ama: / —Échate a los pies, cordera; / y ella lo entendió al revés / y se echó a la cabecera"; "El ama le dijo al cura / que atizara la candela; / y él se lo entendió al revés / y atizó a la cocinera”. En Gerardo López de Guereñu, Refranero alavés, Diputación Foral de Navarra, Vitoria, 1988, p. 48, se recoge el dicho "—¿Han visto las gallinas del señor cura? - ¿Han visto nuestras gallinas? —¿Han visto mis gallinas?” con la explicación de "pequeños, pero esenciales cambios, en las preguntas que solía hacer en el pueblo el ama del párroco, según el tiempo que llevaba a su servicio”. Las raíces sociológicas e históricas del fenómeno han sido agudamente resumidas en IsAbel Testón NúÑEz, Amor, sexo y matrimonio en Extremadura, Universitas, Badajoz, 1985, pp. 189-190: "Las amantes preferidas [de los clérigos] eran las criadas y amas que se encontraban a su servicio. La seducción de estas mujeres era para los clérigos más sencilla y la convivencia con ellas más cómoda, ya que ambos vivían bajo el mismo techo, evitándose de este modo visitas a horas no usuales que propiciaban la crítica y el escándalo social. El cura amancebado con su ama ha sido una estampa clásica del vivir hispano, que no carece de cierta veracidad, al menos en lo concerniente al siglo XVII cacereño. Los clérigos se amancebaban con sus criadas con tanta asiduidad que las autoridades eclesiásticas tuvieron que tomar cartas en el asunto para poner fin a esta conducta con bastante frecuencia. Sobre todo a partir de la década de los ochenta, los visitadores parroquiales de la diócesis de Coria, velando por la recta conducta del clero, les advierten y ordenan «que no se sirban de amas que no tengan de quarenta años arriba, excepto que sean ermanas, sobrinas o dentro del segundo grado...». Evitar la tentación era también evitar el peligro. Y por eso se obligaba a los curas a emplear en las tareas domésticas a mujeres maduras, porque así sería más fácil frenar las pasiones. El clérigo seductor de su ama debió de ser una conducta cotidiana en el ámbito extremeño del siglo xvir. La casuística era muy variada, ya que a veces intervenía el mutuo consentimiento, a veces la tenacidad del pretendiente y en otros casos se hacía necesario el empleo de la violencia y la fuerza por parte del seductor para someter a su víctima”. 
Antón y Teresa,

Bras y su muger, jugaban a el juego

del esconder.

Tapaban a Bras

con un cernaguero

y dice el pandero

que le atapen más,

porque jura Bras

que puede bien uer

a el juego del esconder.

Metiérase Antón

detrás de una artesa,

llamó a su Teresa

diérale un cordón;

que en tal ocasión

no quiere perder

el juego [del esconder].

Bras alzó el artesa

y saliera Antón

con un gran chichón

y otro su Teresa, pero no les pesa

porque es gran plazer

el juego [del esconder].

Echó el brazo al cuello

Antón a Teresa, mill uezes la uesa

y ella gusta de ello, porque tras aquello piensa de hazer

el juego del esconder ${ }^{8}$.

8 Cancionero del Bachiller Jhoan López: Manuscrito 3168 de la Biblioteca Nacional de Madrid, ed. R. J. Gabin, J. Porrúa Turanzas, Madrid, 1980, t. 1, núm. 149. El texto está lleno de palabras de doble sentido erótico, como sucede con el "cordón” y el “chichón”, metáforas respectivas de 'pene' y de ‘erección'. 
Volviendo a la adivinanza documentada por Horozco, López y Correas en los siglos XVI y XVII, la documentación que conocemos muestra que ha llegado con bastante vitalidad a la tradición folclórica de la España moderna. Las siguientes son versiones grabadas por mí de informantes procedentes de pueblos diversos de la geografía española:

El cura y su criada, el sastre y su mujer, se comieron nueve huevos y todos tocaron a tres (Ponteareas, Pontevedra $)^{9}$.

El practicante y su hija y el médico y su mujer se comieron nueve huevos $\mathrm{y}$ todos tocaron a tres

$$
\text { (Mocejón, Toledo) }{ }^{10} \text {. }
$$

El médico y su hija, el practicante y su mujer, cogieron nueve perdices y les tocaron a tres

$$
\text { (Membrilla, Ciudad Real) }{ }^{11} \text {. }
$$

El boticario y su hija, el médico y su mujer, mataron nueve perdices y tocaron a tres

$$
\text { (Acebes del Páramo, León) }{ }^{12} \text {. }
$$

El practicante y su hija, el médico y su mujer,

${ }^{9}$ La informante Sara Nieto, nacida en Ponteareas en 1947, fue entrevistada en Vallecas (Madrid) el 20 de abril de 1993.

${ }^{10} \mathrm{El}$ informante Canuto Pérez, nacido en Mocejón en 1936, fue entrevistado en Vallecas (Madrid) el 21 de abril de 1993.

${ }^{11}$ La informante Carmen Pintado, nacida en Membrilla hace 61 años, fue entrevistada en Vallecas (Madrid) el 11 de mayo de 1993.

${ }^{12} \mathrm{El}$ informante Manuel Cuervo, nacido en Acebes del Páramo (León), fue entrevistado en Villamuñío (León), el 15 de mayo de 1993, en una encuesta realizada junto con Marta y Gerardo Nistal. 
compraron nueve naranjas

y les tocaron a tres

(Villamuñío, León) ${ }^{13}$.

El boticario y su hija, el médico y su mujer, comieron nueve palomas

y a todos les tocó a tres

(Sahagún, León) ${ }^{14}$.

El boticario y su hija, el médico y su mujer, se comieron nueve peras y todos tocaron a tres (Burganes de Valverde, Zamora) ${ }^{15}$.

Resulta curioso comprobar que la adivinanza se está difundiendo también actualmente por cauces nada convencionales. Un niño burgalés de 12 años me comunicó la siguiente versión, que aprendió no de su padre (el informante de Villamuñío que me proporcionó una de las versiones anteriores), sino de su libro de matemáticas de $6^{\circ}$ curso de enseñanza primaria:

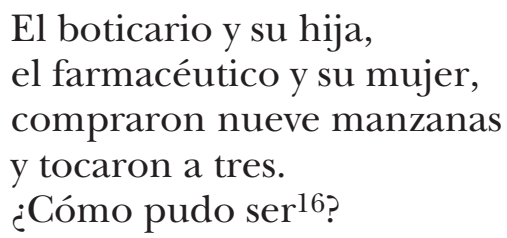

${ }^{13}$ El informante Leovino Nistal, de 53 años, fue entrevistado en Villamuñío (León) el 15 de mayo 1993, en una encuesta realizada junto con Marta y Gerardo Nistal.

${ }^{14}$ El informante Nicolás Fernández, de 84 años, fue entrevistado en Sahagún (León) el 20 de marzo de 1994, en una encuesta realizada junto con Marta Nistal.

${ }^{15}$ La informante Aquilina Zanca, de 66 años, fue entrevistada en Vallecas (Madrid) el 22 de abril de 1993.

${ }^{16} \mathrm{El}$ informante fue Gerardo Nistal, de 12 años, nacido en Burgos y entrevistado en Villamuñío (León) el 15 de mayo de 1993. Aprendió la adivinanza de su libro Pitágoras, preparado por S. Mansilla, María P. Bujanda, y J. Ayuso, SM, Madrid, 1986, p. 134. 
Existe también un cierto número de versiones españolas e hispanoamericanas en castellano publicadas ${ }^{17}$. Y además, se conocen versiones catalanas como la siguiente:

L'apotecària i sa filla, el metge i la seva muller es menjaven nou taronges, cada un se'n va menjar tres ${ }^{18}$.

\title{
Existen también versiones en gallego:
}

\author{
O médico e máis a filla, \\ o estudiante e a muller \\ mercaron nove galiñas \\ e tocáronlles a tres ${ }^{19}$.
}

17 Versiones españolas se han publicado en Fernán Caballero, Cuentos, oraciones, adivinanzas y refranes populares e infantiles, T. Fortanet, Madrid, 1877, pp. 272 y 457; Aurelio de Llano RozA de Ampudia, Esfoyaza de cantares asturianos, Marcelo Morchón, Oviedo, 1924, núm. 1270; Aurelio M. EsPinosa (padre), Cuentos populares españoles, C.S.I.C., Madrid, 1946-1947, núm. 27, donde se da una amplia bibliografía de versiones españolas, hispanoamericanas y europeas; AurELIO M. Espinosa (hijo), Cuentos populares de Castilla y León, C.S.I.C., Madrid, 1988, núms. 261-265 (donde se amplía la bibliografía panhispánica de su padre); JAIme Fernández Riol, "Ochenta adivinanzas leonesas", Revista de Folklore, 1993, núm. 149, p. 175, núm. 21; y José Manuel Fraile Gil, La poesía infantil en la tradición madrileña, Comunidad, Madrid, 1994, p. 343. En cuanto a versiones hispanoamericanas, la misma MARGIT Frenk (Corpus, núm. 1459) ha señalado supervivencias modernas en Argentina y México, publicadas en Juan Alfonso Carrizo, Antecedentes hispano-medievales de la poesía tradicional argentina, Estudios Hispánicos, Buenos Aires, 1945, p. 459; y en el Cancionero folklórico de México, eds. M. Frenk y otros, El Colegio de México, México, 1975-1985, t. 4, núm. 9608. A éstas se pueden añadir otras versiones publicadas en RAfaEl Jijena Sánchez, Adivina adivinador: 500 de las mejores adivinanzas de la lengua española, Albatros, Buenos Aires, 1948, p. 86, núm. 220; J. Alden MAsson, Folklore puertorriqueño t. 1: Adivinanzas, Instituto de Cultura Puertorriqueña, San Juan, 1960, p. 201, núm. 726, y p. 202, núms. 727 y 728; Manuel Rueda, Adivinanzas dominicanas, Universidad Nacional Pedro Henríquez Ureña, Santo Domingo, 1970, p. 365; Jesús M. CARRIzo, Salpicón folklórico de Catamarca, edición del autor, Buenos Aires, 1975, p. 72; y en la reseña de Samuel G. Armistead al Corpus de Frenk, en HR, 57 (1989), p. 505.

18 Joan Amades, Folklore de Catalunya, t. 1: Cançoner, Selecta, Barcelona, 1982, p. 1317, núm. 1246. Véase otra versión catalana en JoAn Castellví Cerdè, Cinccentes endevinalles, 3ํㅡㄹ ed., Eler, Barcelona, 1956, p. 9, núm. 26.

${ }^{19}$ José Luis GÁrfer, y Concha Fernández, Adivinancero popular gallego, Taurus, Madrid, 1984, p. 246. 
Y además, se pueden citar algunas canciones españolas de tradición moderna que parecen enlazar, en su formulística y en algunos de sus tópicos, con la adivinanza que estamos estudiando:

El cura de mi lugar y el sacristán de mi pueblo hacen los hijos a medias y los parten por San Pedro ${ }^{20}$.

El cura de la Acebosa y el sacristán de Ramales hacen los hijos a medias y los reparten a pares.

El herrero y el barbero, el cura y el sacristán tienen los hijos a medias y los parten por San Juan ${ }^{21}$.

El herrero y el barbero, el cura y el sacristán, esos cuatro galapares que no salen del lugar; el herrero $p a$ hacer clavos, el barbero $p a$ afeitar, el cura $p a$ decir misa y el sacristán $p a$ ayudar ${ }^{22}$.

20 Canción recogida por mí al rabelista Donato Muñoz, nacido en 1919 en Valdeprado del Río (Cantabria) y entrevistado en Nestar (Palencia) el 12 de julio de 1989.

${ }^{21}$ Fernando Gomarín Guirado, Cancionero secreto de Cantabria, Universidad de Cantabria, Santander, 1989, núms. 54 y 55. En el Prólogo a este Cancionero (p. 17), Robert Jammes relaciona estas estrofas con la adivinanza antigua recogida por Correas ("El kura i el sakristán...”). Se ha publicado otra versión muy parecida en Claudia de los Santos, Luis Domingo Delgado, e Ignacio Sanz, Folklore segoviano, t. 1: La rueda del año, Caja de Ahorros y Monte de Piedad, Segovia, 1982, p. 127.

22 Antonio Sánchez del Barrio, Danzas de palos, Diputación Provincial, Valladolid, 1986, p. 16. Hay publicadas otras versiones en Luis Díaz Viana, JoAQuín Díaz, y José Delfín Val, Catálogo folklórico de la provincia de Valladolid, t. 5: Cancionero musical, 2ª parte, Institución Cultural Simancas, Valladolid, 1982, p. 256; JoAQuín Díaz, y Luis Díaz Viana, Cancionero de Palencia, Diputación Provincial, Palencia, 1983, t. 2, p. 173; L. DíAz Viana, "La tradición oral de un pueblo castellano", 
El barbero y el herrero, el cura y el sacristán, son los cuatro de mi pueblo que viven sin trabajar $^{23}$.

Un zapatero y un sastre, y un oficial de barbero, son tres personas distintas y ninguno verdadero ${ }^{24}$.

La trinidad de Hornachos; dos putas y un boticario ${ }^{25}$.

El cura y el sacristán andaron a mosquetazos porque el cura se llevaba a la sacristana en brazos ${ }^{26}$.

Rito y tradición oral en Castilla y León, Ámbito, Valladolid, 1984, p. 23; JoAQUín DíAz, "La danza en Lobeznos", en Actas de las I Jornadas de Investigación de danzas guerreras, agrarias, de fertilidad, de paloteo y similares (Fregenal de la Sierra, 24-26/7/1986), ed. J. Marcos Arévalo, Ayuntamiento de Fregenal de la Sierra, Badajoz, 1987, p. 81; e Isidoro Tejero Cobos, Dulzaineros, música y costumbres populares en tierras segovianas, Caja de Ahorros y Monte de Piedad, Segovia, 1990, p. 86.

${ }^{23}$ Manuel Garrido Palacios, "El breve cancionero de la tía Petra (Miranda del Castañar, Salamanca)", Revista de Folklore, 1994, núm. 158, p. 58.

24 Narciso Alonso Cortés, "Cantares populares de Castilla", RHii, 32 (1914), pp. 87-427, reed. Diputación Provincial, Valladolid, 1982, núm. 3271. Véanse otras versiones similares en Francisco Rodríguez Marín, Cantos populares españoles, Francisco Álvarez y Cía., Sevilla, 1882-1883, núm. 7221; Melchor de Palau, Cantares populares y literarios recopilados por... Montaner y Simón, Barcelona, 1900, p. 273; Elviro Martínez, Brujería asturiana, Everest, León, 1987, p. 83; y Juliana Panizo Rodríguez, "Refranes alusivos al trabajo", Revista de Folklore, 1994, núm. 163, p. 36. Yo he grabado como parte de un "brindis" tradicional de Gallegos del Pan (Zamora): "—¿Tú crees que un sastre y un zapatero / y la mujer de un barbero / son tres personas distintas / y ninguna verdadera? / —Sí, creo”. El informante Antonio Fidalgo, nacido en 1960 en Gallegos del Pan, fue entrevistado allí el 5 de agosto de 1989.

25 Antonio Rodríguez-Moñino, Diccionario geográfico popular de Extremadura, Diputación Provincial de Badajoz, Madrid, 1965, núm. 702.

${ }^{26}$ M. L. Escribano Pueo, T. Fuentes Vázquez, F. Morente Muñoz, y A. RoMERo LóPEz, Cancionero granadino de tradición oral, Universidad, Granada, 1994, núm. 419 . 
Puede que tan interesante como la andadura de este motivo folclórico por la tradición hispánica vieja y moderna sea su documentación en otras tradiciones europeas. Una en la que tiene gran difusión es en la de lengua inglesa, que ofrece testimonios - también desde la tradición renacentista a la actual- de gran parecido con los españoles. Peter y Iona Opie publicaron una versión inglesa moderna que reproduzco:

The fiddler and his wife, the piper and his mother, ate three half-cakes, three whole cakes, and three quarters of another ${ }^{27}$.

¿Cuántos comieron cada uno? — se preguntan los folcloristas ingleses-, si la mujer del violinista era la madre del gaitero, cada uno recibió un pastel y tres cuartos. Es posible que esta solución haya sido conocida durante más de trescientos cincuenta años. El autor de The riddles of Heraclitus and Democritus, publicadas por John Norton en 1598, era un hombre con una formación literaria, pero al tiempo que creaba sus propias adivinanzas, reformulaba otras que ya eran populares. La número cuarenta y siete de su colección era:

The Miller, and the Millers wife, that they might merrie make, were set down with a dish of fruite, a cake, and half a cake, the parson of the towne with them, his sister and no more: now haue you heard of all the guests, and of their bread the store.

Yet did they vse the matter with such cunning, skill, and art, that euerie one eate halfe a cake, before they did depart.

Al poema inglés le seguía una explicación que decía que la mujer del molinero era la hermana del clérigo; por lo que el reparto no había sido difícil de hacer. Semejante solución nos confirma la

27 OpIE, The Oxford dictionary of nursery rhymes, Oxford University Press, Oxford, 1989, núm. 165. 
indudable relación entre las dos adivinanzas, la española y la inglesa, documentadas desde el siglo xvi hasta la actualidad; y documentos precursores de una tradición que, en realidad, tiene una amplísima dimensión paneuropea, porque ejemplos de nuestro enigma han sido publicados a lo largo y ancho de toda Europa, y en dominios tan dispares como Irlanda, Bélgica, Alemania o Polonia, lo cual indica que su tradición debía ser probablemente muy anterior a la documentación escrita del siglo Xvi español e inglés ${ }^{28}$. El hecho de que se relacione además con tópicos enigmísticos y cuentísticos de también viejo arraigo internacional ${ }^{29}$ vuelve a ser un indicio que reafirma su antigüedad y su extraordinaria resistencia tradicional multilingüística y multicultural. En el marco de todas estas versiones y tradiciones, el texto y las glosas editados por Sebastián de Horozco hacia 1560-1580 constituyen un hito, ya que son el más viejo testimonio documentado — algunos años anterior a la más antigua versión inglesa publicada- de un enigma que hunde sus raíces en el antiguo fondo folclórico común de los pueblos hispánicos y europeos.

José Manuel Pedrosa Consejo Superior de Investigaciones Científicas

${ }^{28}$ Sobre sus testimonios paneuropeos, véase de Vernam Hull, y ArCher TaYLOR, A collection of Irish riddles, University of California, Berkeley-Los Angeles, 1955, núms. 645 y 646, pp. 81 y 108: "The piper (doctor, clerk) and his wife"; EsPINOSA (padre), Cuentos populares españoles, núm 27; y EsPINOSa (hijo), Cuentos populares de Castilla y León, núms. 261-265.

29 Véase Antti Aarne, \& Stith Thompson, The types of the folktale: A classification and bibliography (second revision), FF Communications, Helsinki, 1981, núm. 1663: "Dividing five eggs equally between two men and one woman"; y REGINETта Навоuсна, Types and motifs of the Judeo-Spanish folktales, Garland, New York-London, 1992, núm. **1658: "Dividing the eggs". 